\title{
Association between hyperthyroidism and risk of incident in Parkinson's disease
}

\author{
Shih-Rong Lin ${ }^{1}$, Shih-Fen Chen ${ }^{2}$, Yu-Cih Yang ${ }^{3}$, Chung-Y Hsu ${ }^{4}$ and Yu-Chih Shen ${ }^{1,5,6}$ \\ ${ }^{1}$ Institute of Medical Sciences, Tzu Chi University, Hualien, Taiwan \\ ${ }^{2}$ Department of Obstetrics and Gynecology, Hualien Tzu Chi Hospital, Buddhist Tzu Chi Medical Foundation, Hualien, Taiwan \\ ${ }^{3}$ Management Office for Health Data, China Medical University Hospital, Taichung, Taiwan \\ ${ }^{4}$ Graduate Institute of Clinical Medical Science, China Medical University, Taichung, Taiwan \\ ${ }^{5}$ Department of Psychiatry, Hualien Tzu Chi Hospital, Buddhist Tzu Chi Medical Foundation, Hualien, Taiwan \\ ${ }^{6}$ School of Medicine, Tzu Chi University, Hualien, Taiwan
}

Correspondence should be addressed to Y-C Shen: shengmp@gmail.com

\begin{abstract}
Hyperthyroidism contributes to many other disease conditions, including neurodegenerative diseases. Parkinson's disease (PD) is one of the most common neurodegenerative diseases. The purpose of this study was to investigate the risk of PD in patients with hyperthyroidism. A total of 8788 patients with hyperthyroidism and 8788 controls (without hyperthyroidism) matched by age, gender, index year, and Charlson Comorbidity Index (CCI) score were enrolled between 2000 and 2012. Patients were then followed until the end of 2013 using Taiwan's National Health Insurance Research Database, at which time participants who developed PD were identified. Cox regression analysis was used to calculate the hazard ratio (HR) with a $95 \% \mathrm{Cl}$ of PD incidence rate between patients with hyperthyroidism and unaffected controls. Patients with hyperthyroidism had a significantly increased risk of PD compared with unaffected controls (1.21 vs 0.45 per 1000 person-years, HR: 2.69, 95\% CI: 1.08-6.66) after adjusting for age, gender, $\mathrm{CCl}$ score, comorbidities, and antithyroid therapy. Hyperthyroidism and PD may share common manifestations. After excluding the first year of observation, a similar result is obtained (HR: $2.57,95 \% \mathrm{Cl}: 1.61-4.01)$. Also, this study found that older age (HR: 3.74-8.53), more comorbidities (HR: 1.58-1.63), and specific comorbidities (brain injury (HR: 1.57) and cerebrovascular disease (HR: 3.44)) were associated with an increased risk of developing PD. Patients with hyperthyroidism have an increased risk of developing PD. Additional prospective clinical studies are warranted to examine the relationship between hyperthyroidism and PD and determine if there is an intervention that could reduce PD risk.
\end{abstract}
Key Words
- hyperthyroidism
- Parkinson's disease
- cohort

\section{Introduction}

Hyperthyroidism is a condition in which excess thyroid hormone is synthesized and secreted by the thyroid gland. The prevalence of symptomatic hyperthyroidism is approximately $0.5 \%$ and varies geographically (1). In Taiwan, the prevalence of symptomatic hyperthyroidism is $0.37 \%$, and the leading causes of hyperthyroidism are Graves' disease (95\%), followed by toxic nodular goiter
(2\%) and other causes (3\%) (2). Hyperthyroidism has been implicated in many other diseases and is widely studied for its association with cardiovascular disease (3). Hyperthyroidism has also been shown to contribute to periodic thyrotoxic paralysis, osteoporosis, and abnormalities of the reproductive system, as well as neurodegenerative diseases (1). (c) 2021 The authors Published by Bioscientifica Ltd
This work is licensed under a Creative Commons Attribution-NonCommercial-NoDerivatives 4.0 Internationab ticense.ifica com at $04 / 25 / 2023$ 11:18:26PM 
Parkinson's disease (PD) is one of the most common neurodegenerative diseases and is characterized by the progressive loss of dopaminergic neurons in the substantia nigra (4). The cause of PD remains unknown; however, genetic and environmental factors have been implicated (4). Genetic association studies have identified several loci that are significantly associated with PD (4). An increased risk in individuals exposed to pesticides and those who have suffered head injuries has also been demonstrated (4).

Epidemiological evidence has suggested a link between hyperthyroidism and incident PD. A nationwide population-based cohort study in Sweden that followed 34,735 patients with Graves' disease/hyperthyroidism has reported a 1.42-fold increased risk of developing PD (5). Another nationwide case-control study in Denmark that retrospectively followed 13,695 patients with PD has reported twice the risk of developing PD in patients with a prior diagnosis of Graves' disease/hyperthyroidism (6). The two studies previously used data from the inpatient registry without outpatient records, which may underestimate those with less severe illness conditions. Besides, they did not have access to the drug/surgery database, limiting them from using this database to confirm the diagnosis of hyperthyroidism/PD or to study the influence of antithyroid therapy on the risk of incident PD.

To more fully determine if hyperthyroidism is linked to an increased risk of incident PD, Taiwan's National Health Insurance Research Database (NHIRD), a nationally representative database of medical claims, was used to conduct a longitudinal follow-up study of the risk of PD in patients with hyperthyroidism.

\section{Subjects and methods}

\section{Data source}

The National Health Insurance Program of Taiwan (NHIP) was established in 1995 to offer national healthcare via a single-payer government-mandated insurance coverage plan. The NHIP covers 23 million individuals in Taiwan and is one of the world's largest and most extensive population databases. The NHIRD contains all insurance coverage claims data and associated medical information for $>99 \%$ of Taiwan's population. The database consists of comprehensive data for covered individuals, including demographic data, disease diagnoses, medical procedures, and other related information. Disease diagnoses were coded to reflect the International Classification of Diseases, 9th Revision, Clinical Modification (ICD9-CM) coding. Several subsets of data have been created within the NHIRD, including the one used for this study (The Longitudinal Health Insurance Database 2000 (LHID2000)). LHID2000 includes all healthcare information for 1,000,000 individuals randomly chosen from NHIRD between 1995 and 2013 (roughly 4\% of Taiwan's population). The population was selected to be representative of the overall NHIRD population and the country as a whole.

\section{Inclusion criteria}

Patients newly diagnosed with hyperthyroidism (ICD9-CM code: 242) between 2000 and 2012 in LHID2000 were considered for inclusion in the case cohort. For a reliable diagnosis, the case cohort included only those individuals who had been treated with antithyroid drugs (propylthiouracil, thiamazole, and carbimazole), radioactive iodine ablation, or surgery (thyroidectomy) during the follow-up period. In terms of timing, the first diagnosis of hyperthyroidism was defined as the index date. Individuals with a history of PD (ICD-9-CM codes: 332) between 1995 and the index date were eliminated from the case cohort.

For each patient in the case cohort, one control subject matched by age, gender, index year, and Charlson Comorbidity Index (CCI) score was identified from the LHID2000 database (control cohort). Individuals diagnosed with hyperthyroidism or those who had been treated with the previous treatment for hyperthyroidism at any time, and those with a history of PD between 1995 and the index date were excluded from consideration in the control cohort.

\section{Outcome}

Patients newly diagnosed with PD by a board-certified neurologist were considered as incidents. To ensure the validity of $\mathrm{PD}$ diagnosis, only those with prescription records for anti-parkinsonian drugs (L-dopa or dopamine agonists) were calculated as incidents. Those who had neuroleptics or metoclopramide prescription records in the 180 days before the incident PD were excluded from the calculation as incidents. All patients in the current study were followed until the appearance of PD, (c) 2021 The authors Published by Bioscientifica Ltd
This work is licensed under a Creative Commons Attribution-NonCommercial-NoDerivatives 4.0 elnternationab ficense.ifica .com at 04/25/2023 11:18:26PM 
their removal from the NHIP, death, or the end of 2013 (whichever came first).

\section{Covariates}

Baseline demographic information on age $(<50,50-65$, and $>65$ years), gender, and CCI score $(0,1-2, \geq 3)$ were collected for each subject. The CCI score was calculated by summing the weight scores for 19 medical conditions based on their potential influence on mortality and was used to quantify the overall burden of physical comorbidities (7). Also, information on some comorbidities commonly associated with hyperthyroidism or PD were collected for each subject $(1,4)$, including brain injury (ICD-9-CM code: $850-854$, 959.01), cerebrovascular disease (430-438), hypertension (401-405), dyslipidemia (272.0-272.4), and diabetes mellitus (250). During the follow-up period, information on antithyroid drugs (propylthiouracil, thiamazole, and carbimazole), radioactive iodine ablation, or surgery (thyroidectomy) in the case cohort was collected.

\section{Statistical analysis}

For comparisons of demographic characteristics between the case cohort and the control cohort, the chi-square test for nominal variables and the Wilcoxon's sum-rank was used for continuous variables.

The PD incidence rate was estimated by the number of incidents divided by the person-years of follow-up. Kaplan-Meier analysis with a log-rank test was used to determine the difference in PD's cumulative incidence for the two cohorts.

Cox regression analysis was used to calculate the crude and adjusted hazard ratio (HR) with a 95\% CI of the PD incidence rate between the two cohorts. Variables controlled in the adjusted HR calculation included age, gender, CCI score, and comorbidities (brain injury, cerebrovascular disease, hypertension, dyslipidemia, and diabetes mellitus). Antithyroid therapies (antithyroid drugs, radioactive iodine ablation, and surgery) were fitted into the model and treated as time-dependent covariates.

Table 1 Demographic characteristics of patients with hyperthyroidism and comparative controls at baseline and during the follow-up period.

\begin{tabular}{l} 
Variables \\
Baseline \\
Age \\
$<50$ \\
$50-65$ \\
$>65$ \\
Gender \\
Female \\
Male \\
CCI score \\
0 \\
$1-2$ \\
$\geq 3$ \\
Comorbidity \\
Brain injury \\
Cerebrovascular disease \\
Hypertension \\
Dyslipidemia \\
Diabetes mellitus \\
Follow-up period \\
Treatment \\
Antithyroid drugs \\
Radioactive iodine ablation \\
Surgery \\
Parkinson's disease \\
Age at diagnosis (SD), years \\
Mean duration between enrollment and diagnosis (SD), \\
years \\
\hline
\end{tabular}

\begin{tabular}{|c|c|}
\hline \multicolumn{2}{|c|}{$\begin{array}{c}\text { Patients with } \\
\text { hyperthyroidism }\end{array}$} \\
\hline \multicolumn{2}{|c|}{$n=8788$} \\
\hline$n$ & $\%$ \\
\hline 6552 & 74.6 \\
\hline 1604 & 18.2 \\
\hline 632 & 7.2 \\
\hline 6745 & 76.8 \\
\hline 2043 & 23.2 \\
\hline 8072 & 91.9 \\
\hline 592 & 6.7 \\
\hline 124 & 1.4 \\
\hline 334 & 3.8 \\
\hline 408 & 4.6 \\
\hline 1214 & 13.8 \\
\hline 1364 & 15.5 \\
\hline 1153 & 13.1 \\
\hline 8732 & 99.4 \\
\hline 167 & 1.9 \\
\hline 905 & 10.3 \\
\hline 85 & 1.0 \\
\hline $63.1(13$ & \\
\hline 8.0 & \\
\hline
\end{tabular}

\begin{tabular}{|c|c|c|}
\hline \multicolumn{2}{|c|}{$\begin{array}{l}\text { Patients without } \\
\text { hyperthyroidism }\end{array}$} & \multirow[b]{3}{*}{$P$-value } \\
\hline \multicolumn{2}{|c|}{$n=8788$} & \\
\hline$n$ & $\%$ & \\
\hline & & - \\
\hline 6552 & 74.6 & \\
\hline 1604 & 18.2 & \\
\hline 632 & 7.2 & \\
\hline & & - \\
\hline 6745 & 76.8 & \\
\hline 2043 & 23.2 & \\
\hline 8072 & 91.9 & - \\
\hline 592 & 6.7 & \\
\hline 124 & 1.4 & \\
\hline 321 & 3.7 & 0.60 \\
\hline 361 & 4.1 & 0.08 \\
\hline 968 & 11.0 & $<0.01$ \\
\hline 903 & 10.2 & $<0.01$ \\
\hline 689 & 7.8 & $<0.01$ \\
\hline & & - \\
\hline 32 & 0.4 & $<0.01$ \\
\hline $63.1(12.4)$ & & 0.94 \\
\hline $8.0(3.9)$ & & 0.97 \\
\hline
\end{tabular}

aChi-square test; bWilcoxon's rank-sum test.

$\mathrm{CCl}$, Charlson Comorbidity Index.

https://ec.bioscientifica.com https://doi.org/10.1530/EC-20-0554 (c) 2021 The authors Published by Bioscientifica Ltd

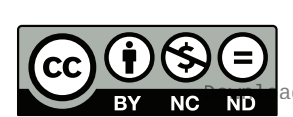

This work is licensed under a Creative Commons Attribution-NonCommercial-NoDerivatives 4.0 Internationad ticense ifica.com at 04/25/2023 11:18:26PM 
Table 2 Cox regression analyses of demographic characteristics associated with Parkinson's disease for the entire cohort.

\begin{tabular}{l}
\hline Variables \\
\hline Hyperthyroidism \\
No \\
Yes \\
Age \\
$<50$ \\
$50-65$ \\
$>65$ \\
Gender \\
Female \\
Male \\
CCI score \\
0 \\
$1-2$ \\
$\geq 3$ \\
Comorbidities \\
Brain injury \\
No \\
Yes \\
Cerebrovascular disease \\
No \\
Yes \\
Hypertension \\
No \\
Yes \\
Dyslipidemia \\
No \\
Yes \\
Diabetes mellitus \\
No \\
Yes \\
\hline \\
\hline
\end{tabular}

\begin{tabular}{|c|c|c|}
\hline PD & Person years & $\mathbf{I R}^{\mathbf{a}}$ \\
\hline 32 & 70,370 & 0.45 \\
\hline 85 & 70,486 & 1.21 \\
\hline 18 & 108,752 & 0.17 \\
\hline 47 & 24,556 & 1.91 \\
\hline 52 & 7548 & 6.89 \\
\hline 91 & 109,490 & 0.83 \\
\hline 26 & 31,366 & 0.83 \\
\hline 74 & 131,551 & 0.56 \\
\hline 36 & 8123 & 4.43 \\
\hline 7 & 1182 & 5.92 \\
\hline 100 & 134,505 & 0.74 \\
\hline 17 & 6351 & 2.67 \\
\hline 71 & 133,578 & 0.53 \\
\hline 46 & 7278 & 6.32 \\
\hline 86 & 119,236 & 0.72 \\
\hline 31 & 21,620 & 1.43 \\
\hline 85 & 118,408 & 0.72 \\
\hline 32 & 22,448 & 1.42 \\
\hline 88 & 123,500 & 0.71 \\
\hline 29 & 17,356 & 1.67 \\
\hline
\end{tabular}

\begin{tabular}{|c|c|}
\hline Crude $^{\mathbf{b}}$ HR $(95 \% \mathrm{Cl})$ & Adjusted $^{\mathbf{c}}$ HR $(95 \% \mathrm{Cl})$ \\
\hline $\begin{array}{c}1 \text { (Reference) } \\
2.65(1.77-3.99)^{*}\end{array}$ & $\begin{array}{c}1 \text { (Reference) } \\
2.69(1.08-6.66)^{\star}\end{array}$ \\
\hline $\begin{array}{c}1 \text { (Reference) } \\
11.7(6.81-20.2)^{*} \\
43.5(25.4-74.6)^{*}\end{array}$ & $\begin{array}{c}1 \text { (Reference) } \\
3.74(2.85-4.92)^{*} \\
8.53(3.58-12.7)^{\star}\end{array}$ \\
\hline $\begin{array}{c}1 \text { (Reference) } \\
0.99(0.64-1.54)\end{array}$ & $\begin{array}{c}1 \text { (Reference) } \\
0.86(0.54-1.37)\end{array}$ \\
\hline $\begin{array}{c}1 \text { (Reference) } \\
7.95(5.33-11.8)^{*} \\
11.0(5.05-23.9)^{*}\end{array}$ & $\begin{array}{c}1 \text { (Reference) } \\
1.58(1.13-2.21)^{\star} \\
1.63(1.25-3.34)^{*}\end{array}$ \\
\hline $\begin{array}{c}1 \text { (Reference) } \\
3.58(2.14-6.00)^{*}\end{array}$ & $\begin{array}{c}1 \text { (Reference) } \\
1.57(1.03-2.53)^{\star}\end{array}$ \\
\hline $\begin{array}{c}1 \text { (Reference) } \\
11.9(8.20-17.2)^{*}\end{array}$ & $\begin{array}{c}1 \text { (Reference) } \\
3.44(2.27-5.21)^{*}\end{array}$ \\
\hline $\begin{array}{c}1 \text { (Reference) } \\
1.98(1.31-2.99)^{*}\end{array}$ & $\begin{array}{c}1 \text { (Reference) } \\
1.08(0.69-1.69)\end{array}$ \\
\hline $\begin{array}{c}1 \text { (Reference) } \\
1.97(1.31-2.97)^{*}\end{array}$ & $\begin{array}{c}1 \text { (Reference) } \\
1.29(0.83-2.01)\end{array}$ \\
\hline $\begin{array}{c}1 \text { (Reference) } \\
2.33(1.53-3.55)^{*}\end{array}$ & $\begin{array}{c}1 \text { (Reference) } \\
1.26(0.81-1.97)\end{array}$ \\
\hline
\end{tabular}

aper 1000 person-years; brelative hazard ratio; cadjusted for hyperthyroidism, age, gender, CCl score, comorbidities and antithyroid therapy in Cox regression analyzes (antithyroid therapy, including antithyroid drugs, radioactive iodine ablation, and surgery, were treated as time-dependent covariates); ${ }^{*}$-value $<0.05$.

$\mathrm{CCl}$, Charlson Comorbidity Index; HR, hazard ratio; IR, incidence rates; PD, Parkinson's disease.

Except for the overall risk assessment for PD between the two cohorts, we performed age and gender stratification analyses. Also, hyperthyroidism and PD have common manifestations, such as tachycardia, heat intolerance, emotional lability, hot flashes, sweating, and tremors, which makes differential diagnosis more difficult (8). We performed a sensitivity analysis to minimize the influence of potential bias by excluding the first year of observation. The significance level of all tests was set at 0.05. SAS 9.4 software (SAS Institute Inc., Cary, NC) was used to conduct these analyses.

\section{Results}

\section{Demographic status}

The baseline demographic characteristics of patients with hyperthyroidism (case cohort) and the comparative controls (control cohort) are shown in Table 1. Overall,
8788 patients with hyperthyroidism were matched to 8788 controls by age, gender, index year, and CCI score. The age distribution in the two cohorts was $74.6 \%$ for those $<50$ years, $18.2 \%$ for those $50-65$ years, and $7.2 \%$ for those $>65$ years of age. The two cohorts had more females than males $(76.8 \%$ vs $23.2 \%)$. The distribution of CCI scores in both cohorts was $91.9 \%$ for $0,6.7 \%$ for $1-2$, and $1.4 \%$ for $\geq 3$. The case cohort had a higher prevalence of hypertension $(13.8 \%$ vs $11.0 \%, P<0.01)$, dyslipidemia ( $15.5 \%$ vs $10.2 \%, P<0.01)$, and diabetes mellitus ( $13.1 \%$ vs $7.8 \%, P<0.01)$, compared to the control cohort. Regarding the two comorbidities (brain injury and cerebrovascular disease), the two cohorts' prevalence is similar.

During follow-up, antithyroid drugs (99.4\%) were the most commonly used treatment in the case cohort, followed by surgery (10.3\%) and radioactive iodine ablation (1.9\%). The mean age at diagnosis of PD (around 63.1 years) and duration of follow-up (8.0 years) were similar for the two cohorts. At the end of the follow-up,

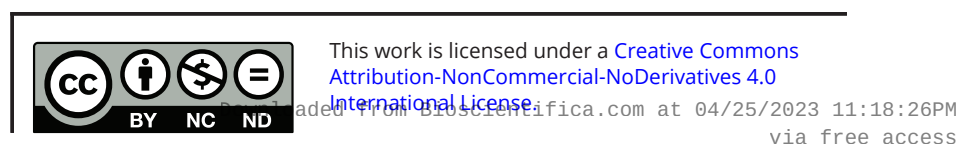


the frequency of incident SLE was significantly higher in the case cohort than in the control cohort $(1.0 \%$ vs $0.4 \%, P<0.01)$.

\section{Risk of PD}

The incidence rates for PD were 1.21 (case cohort) and 0.45 (control cohort) per 1000 person-years, respectively (Table 2). After adjusting for the covariates mentioned previously, the case cohort had a significantly higher risk of PD than the control cohort (HR: 2.69, 95\% CI: 1.08-6.66). Kaplan-Meier analysis with a log-rank test also revealed a significant association between having hyperthyroidism and the subsequent risk of $\mathrm{PD}(P<0.01$; Fig. 1$)$.

For the entire cohort, after adjusting for the covariates mentioned previously, the risk of PD was higher for those aged 50-65 (HR: 3.74, 95\% CI: 2.85-4.92) and >65 years (HR: 8.53, 95\% CI: 3.58-12.7) than for those $<50$ years. There was no significant difference in the risk estimate for PD between the two genders. Also, compared to patients whose baseline CCI score was 0 , those with a CCI score of 1-2 (HR: 1.58, 95\% CI: 1.13-2.21) and $\geq 3$ (HR: 1.63, 95\% CI: 1.25-3.34) were associated with a higher risk of PD after adjusting for the covariates mentioned previously. Regarding baseline comorbidities, brain injury (HR: 1.57, 95\% CI: 1.03-2.53), cerebrovascular disease (HR: 3.44, 95\% CI: 2.27-5.21) were associated with an increased risk of incident PD after adjusting for the covariates mentioned previously. There was no significant difference in the

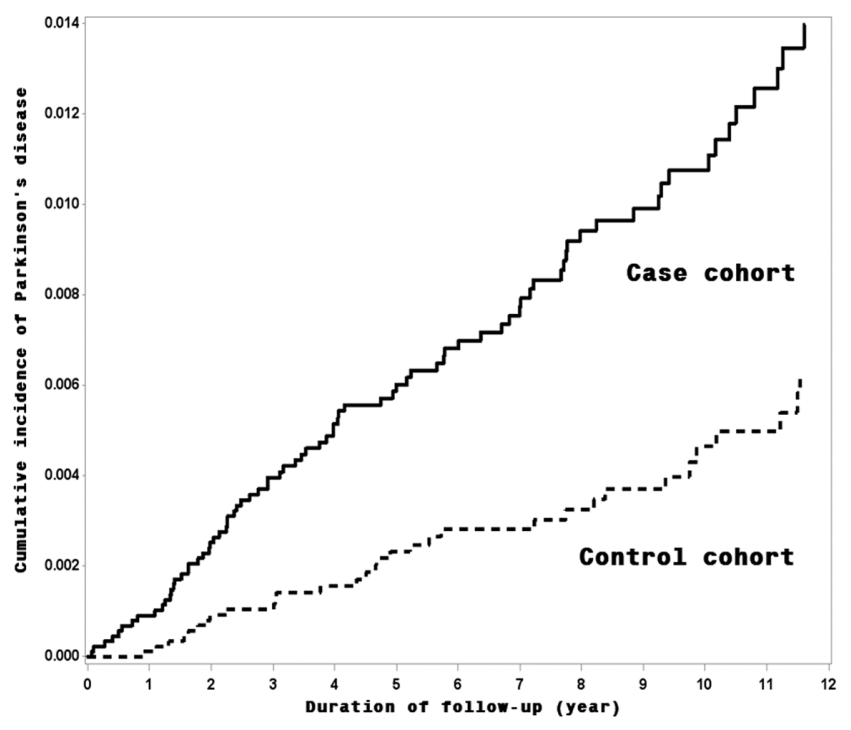

Figure 1

Cumulative incidence of Parkinson's disease in patients with hyperthyroidism (case cohort) and comparative controls (control cohort). Kaplan-Meier analysis with a log-rank test revealed a significant association between the case cohort and Parkinson's disease $(P<0.01)$ estimation of the PD risk in the presence of hypertension, dyslipidemia, or diabetes mellitus.

\section{Stratification analysis}

Table 3 also showed the incidence rates of PD in the case cohort and the control cohort stratified by age and gender. The case cohort had a higher incidence of PD than the control cohort in all age and gender subgroups.

After adjusting for the covariates mentioned previously, the case cohort had a significantly higher risk of PD than the control cohort in specific age subgroups (50-65 years - HR: 3.65, 95\% CI: 1.87-7.66; >65 years HR: 4.07, 95\% CI: 1.97-4.78) and female subgroup (HR: 2.95, 95\% CI: $1.11-4.73)$.

\section{Sensitivity analysis}

As shown in Table 4, after excluding the first year of observation, the case cohort still had a significantly higher risk of PD than the control cohort after adjusting for the above variables (HR: 2.57, 95\% CI: 1.61-4.01).

\section{Discussion}

This population-based cohort study examined the risk of PD in patients with hyperthyroidism using age-, gender-, index year-, and CCI score-matched cohort with a maximum follow-up period of 13 years in a nationally representative sample. The study demonstrated that patients with hyperthyroidism had an increased risk of PD compared with unaffected controls. This finding was consistent with reports of population-based studies in Sweden and Denmark $(5,6)$. Unique to the two studies, this study contained outpatient records and took into account antithyroid therapy's effect on the risk of incidence of PD. Hyperthyroidism should still be considered an independent risk factor for PD because, after adjustment for the impact of antithyroid therapy, a significant risk association has been observed.

There are possible explanations that may account for the mechanisms underlying this observation. First, hyperthyroidism has been linked to increased oxidative stress and a deregulated inflammatory response in adult patients (9). Since persistent oxidative stress and neuroinflammation has been linked to both the initiation and progression of PD (10), hyperthyroidism may serve as a possible contributing factor to the development of PD through these mechanisms (11). Second, Graves' disease

This work is licensed under a Creative Commons Attribution-NonCommercial-NoDerivatives 4.0 International License ifica com at $04 / 25 / 2023$ 11:18:26PM 
Table 3 Cox regression analyses of overall risk of Parkinson's disease among patients with hyperthyroidism and comparative controls, then stratified by age and gender.

\begin{tabular}{|c|c|c|c|c|c|c|c|c|}
\hline \multirow[b]{2}{*}{ Variables } & \multicolumn{3}{|c|}{ Patients with hyperthyroidism } & \multicolumn{3}{|c|}{$\begin{array}{l}\text { Patients without } \\
\text { hyperthyroidism }\end{array}$} & \multirow[b]{2}{*}{ Crude ${ }^{\mathbf{b}}$ HR $(95 \% \mathrm{Cl})$} & \multirow[b]{2}{*}{ Adjusted $^{\mathbf{c}} \mathbf{H R}(95 \% \mathrm{Cl})$} \\
\hline & PD & Person years & $\mathrm{IR}^{\mathrm{a}}$ & PD & Person years & $\mathrm{IR}^{\mathrm{a}}$ & & \\
\hline $\begin{array}{l}\text { Total } \\
\text { Age }\end{array}$ & 85 & 70,486 & 1.21 & 32 & 70,370 & 0.45 & $2.65(1.77-3.99)^{*}$ & $2.69(1.08-6.66)^{\star}$ \\
\hline$<50$ & 12 & 54,562 & 0.22 & 6 & 54,190 & 0.11 & $1.99(0.75-5.32)$ & $1.98(0.97-5.73)$ \\
\hline $50-65$ & 35 & 12,219 & 2.86 & 12 & 12,336 & 0.97 & $2.98(1.54-5.75)^{*}$ & $3.65(1.87-7.66)^{*}$ \\
\hline$>65$ & 38 & 3705 & 10.3 & 14 & 3844 & 3.64 & $2.82(1.53-5.22)^{*}$ & $4.07(1.97-4.78)^{*}$ \\
\hline \multicolumn{9}{|l|}{ Gender } \\
\hline Female & 67 & 54,819 & 1.22 & 24 & 54,671 & 0.44 & $2.78(1.74-4.44)^{*}$ & $2.95(1.11-4.73)^{\star}$ \\
\hline Male & 18 & 15,667 & 1.15 & 8 & 15,699 & 0.51 & $2.27(0.99-5.24)$ & 2.35 (0.89-4.73) \\
\hline
\end{tabular}

aper 1000 person-years; brelative hazard ratio; cadjusted for hyperthyroidism, age, gender, CCl score, comorbidities and antithyroid therapy in Cox regression analyzes (antithyroid therapy, including antithyroid drugs, radioactive iodine ablation, and surgery, were treated as time-dependent covariates); ${ }^{*}$-value $<0.05$.

$H R$, hazard ratio; IR, incidence rates; PD, Parkinson's disease.

is considered an autoimmune disease that affects the thyroid and is the leading cause of hyperthyroidism in Taiwan (12). A previous study found that Graves' disease may share genetic pathways with PD and is closely linked to PD's specific clinical manifestations (13). Amplified autoimmune reactions of Graves' disease via shared genetic pathways may also contribute to PD development (14). Third, hyperthyroidism triggers symptoms in patients with subclinical vulnerability to PD by acting on PD's biological substrate. For example, the thyroid hormone can increase dopamine catabolism or alter dopamine receptors' sensitivity (15), which may cause symptoms in patients vulnerable to $\mathrm{PD}$. It should be mentioned that these explanations should be considered preliminary and that the mechanisms of detail are worth studying in the future.

Besides, this study found that older age, more comorbidities, and specific comorbidities (brain injury and cerebrovascular disease) were associated with an increased risk of developing PD. Sufficient evidence shows that age is the most critical risk factor for PD, where the incidence of PD begins to rise sharply after age 60 (16); this study confirms this finding. More medical comorbidities and specific comorbidities (brain injury and cerebrovascular disease) may increase the risk of developing PD are consistent with the previous results, which could be the possibility of a direct cause-effect relationship pathophysiological vulnerabilities shared (4). However, we still considered hyperthyroidism as an independent risk factor for PD because a significant risk association was found after adjusting for these comorbidities.

In the stratification analysis, similar risk associations linking hyperthyroidism to subsequent PD were found in all stratified age and gender subgroups (adjusted HR all $>1$ ). However, a relatively small number of PD incidents could result in HR estimates having a wider 95\% CI in some age and gender subgroups and therefore become statistically insignificant. Further studies with a larger sample that could adequately adjust all of the model's confounders are warranted.

This study's strengths include the large populationbased cohort, adjustment for known risk factors, and long period of observation. This study also contains outpatient records and considers the effect of antithyroid therapy on the risk of incident PD, which is unique to the previous

Table 4 Sensitivity analyses of developing Parkinson's disease among patients with hyperthyroidism and comparative controls.

\begin{tabular}{|c|c|c|c|c|c|}
\hline Hyperthyroidism & PD & Person years & $\mathbf{I R}^{\mathbf{a}}$ & Crude $^{\mathbf{b}} \mathbf{H R}(95 \% \mathrm{Cl})$ & Adjusted ${ }^{\mathbf{c}} \mathbf{H R}(95 \% \mathrm{Cl})$ \\
\hline \multicolumn{6}{|l|}{ Not excluding } \\
\hline No & 32 & 70,370 & 0.45 & 1 (Reference) & 1 (Reference) \\
\hline Yes & 85 & 70,486 & 1.21 & $2.65(1.77-3.99)^{*}$ & $2.69(1.08-6.66)^{*}$ \\
\hline \multicolumn{6}{|l|}{$>1$ yeare $^{\mathrm{e}}$} \\
\hline No & 31 & 70,331 & 0.44 & 1 (Reference) & 1 (Reference) \\
\hline Yes & 77 & 70,458 & 1.09 & $2.48(1.63-3.77)^{\star}$ & $2.57(1.61-4.01)^{\star}$ \\
\hline
\end{tabular}

aper 1000 person-years; 'brelative hazard ratio; cadjusted for hyperthyroidism, age, gender, CCI score, comorbidities and antithyroid therapy in Cox regression analyzes (antithyroid therapy, including antithyroid drugs, radioactive iodine ablation, and surgery, were treated as time-dependent covariates); ${ }^{*}$-value $<0.05$.

$\mathrm{HR}$, hazard ratio; IR, incidence rates; PD, Parkinson's disease.

https://ec.bioscientifica.com https://doi.org/10.1530/EC-20-0554 (c) 2021 The authors Published by Bioscientifica Ltd

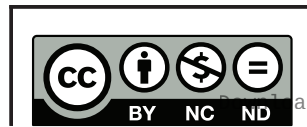

This work is licensed under a Creative Commons Attribution-NonCommercial-NoDerivatives 4.0 elnternational dicense ifica. com at 04/25/2023 11:18:26PM 
two population-based studies $(5,6)$. However, several limitations should also be noted. First, only patients who sought medical help for the diagnosis and treatment of hyperthyroidism or PD were included; therefore, patient identification may have been biased and may have weakened the observed association. However, the patients identified in the current study were confirmed by their treatment, which improved diagnostic validity. Second, the presentation of symptoms for hyperthyroidism and PD and detailed laboratory data such as thyroid hormone levels are not available in the Taiwan NHIRD database. Therefore, additional analyses could not be applied, such as the relationship between thyroid hormone levels and PD symptoms. Third, hyperthyroidism and PD share common manifestations, making a differential diagnosis more difficult (8). Although a sensitivity analysis was performed to minimize potential bias by excluding the first year of observation, the inclusion of false positives is a common concern. Finally, Taiwan NHIRD does not have information on some known risk or protective factors associated with PD, such as family history, pesticide exposure, smoking habits, and coffee drinking (4). Therefore, the contributions of these factors could not be further evaluated.

This study shows that hyperthyroidism is associated with an increased risk of PD, corroborating previous studies in Sweden and Denmark. Further prospective studies on the pathogenesis between hyperthyroidism and $\mathrm{PD}$ and determine if an intervention could reduce the risk of PD are warranted.

\section{Declaration of interest}

The authors declare that there is no conflict of interest that could be perceived as prejudicing the impartiality of the research reported.

\section{Funding}

This study is supported in part by the Taiwan Ministry of Health and Welfare Clinical Trial Center (MOHW109-TDU-B-212-114004); MOST Clinical Trial Consortium for Stroke, Taiwan (MOST 108-2321-B-039-003); Tseng-Lien Lin Foundation, Taichung, Taiwan; Buddhist Tzu Chi Medical Foundation, Taiwan (TCMF-MP 108-01-03). The funding source has no further role in study design; in the collection, analysis, and interpretation of data; in the report's writing; and in the decision to submit the paper for publication.

\section{Data availability}

The data are available, on request, from the corresponding author.

\section{Statement of ethics}

This research was monitored by the Institutional Review Board of China Medical University (CMUH104-REC2-115). All study approaches followed the appropriate standards and policies. The need for informed consent from individual subjects was waived because the LHID2000 contains only anonymized secondary data.

\section{Author contribution statement}

S R Lin and S F Chen managed the literature searches and wrote the 'Introduction' of the manuscript. Y C Yang and C Y Hsu did all the analyses and wrote the 'Method and results' of the manuscript. Y C Shen conceived the study and wrote the 'Discussion' of the manuscript. All authors have approved the final manuscript.

\section{Acknowledgements}

Usha S-Lanstad: (659412)Bloomsbury/Decolonizing Methodologies/Copy editing/Collation by PE/SE team and PDF generation.

\section{References}

1 De Leo S, Lee SY \& Braverman LE. Hyperthyroidism. Lancet 2016388 906-918. (https://doi.org/10.1016/S0140-6736(16)00278-6)

2 Kornelius E, Yang YS, Huang CN, Wang YH, Lo SC, Lai YR \& Chiou JY. The trends of hyperthyroidism treatment in Taiwan: a nationwide population-based study. Endocrine Practice $20182 \mathbf{4}$ 573-579. (https://doi.org/10.4158/EP-2017-0266)

3 Selmer C, Olesen JB, Hansen ML, von Kappelgaard LM, Madsen JC, Hansen PR, Pedersen OD, Faber J, Torp-Pedersen C \& Gislason GH. Subclinical and overt thyroid dysfunction and risk of all-cause mortality and cardiovascular events: a large population study. Journal of Clinical Endocrinology and Metabolism 201499 2372-2382. (https:// doi.org/10.1210/jc.2013-4184)

4 Kalia LV \& Lang AE. Parkinson's disease. Lancet 2015386 896-912. (https://doi.org/10.1016/S0140-6736(14)61393-3)

5 Li X, Sundquist J \& Sundquist K. Subsequent risks of Parkinson disease in patients with autoimmune and related disorders: a nationwide epidemiological study from Sweden. Neuro-Degenerative Diseases 201210 277-284. (https://doi.org/10.1159/000333222)

6 Rugbjerg K, Friis S, Ritz B, Schernhammer ES, Korbo L \& Olsen JH. Autoimmune disease and risk for Parkinson disease: a populationbased case-control study. Neurology 200973 1462-1468. (https://doi. org/10.1212/WNL.0b013e3181c06635)

7 Charlson ME, Pompei P, Ales KL \& MacKenzie CR. A new method of classifying prognostic comorbidity in longitudinal studies: development and validation. Journal of Chronic Diseases 198740 373-383. (https://doi.org/10.1016/0021-9681(87)90171-8)

8 Lavy S, Marks ES \& Abramsky O. Parkinsonism and hyperthyroidism. European Neurology 197412 20-27. (https://doi. org/10.1159/000114600)

9 Mancini A, Di Segni C, Raimondo S, Olivieri G, Silvestrini A, Meucci E \& Curro D. Thyroid hormones, oxidative stress, and inflammation. Mediators of Inflammation 201620166757154. (https://doi.org/10.1155/2016/6757154)

10 Solleiro-Villavicencio H \& Rivas-Arancibia S. Effect of chronic oxidative stress on neuroinflammatory response mediated by CD4(+) $\mathrm{T}$ cells in neurodegenerative diseases. Frontiers in Cellular Neuroscience 201812 114. (https://doi.org/10.3389/fncel.2018.00114)

11 Villanueva I, Alva-Sanchez C \& Pacheco-Rosado J. The role of thyroid hormones as inductors of oxidative stress and neurodegeneration. Oxidative Medicine and Cellular Longevity 20132013 218145. (https:// doi.org/10.1155/2013/218145)

12 Liu CC, Li CY, Lee PC \& Sun Y. Variations in incidence and prevalence of Parkinson's disease in Taiwan: a population-based nationwide study. Parkinson's Disease 20162016 8756359. (https:// doi.org/10.1155/2016/8756359) 
13 Witoelar A, Jansen IE, Wang Y, Desikan RS, Gibbs JR, Blauwendraat C, Thompson WK, Hernandez DG, Djurovic S, Schork AJ, et al. Genome-wide pleiotropy between Parkinson disease and autoimmune diseases. JAMA Neurology $2017 \mathbf{7 4}$ 780-792. (https://doi.org/10.1001/jamaneurol.2017.0469)

14 Jiang T, Li G, Xu J, Gao S \& Chen X. The challenge of the pathogenesis of Parkinson's disease: is autoimmunity the culprit? Frontiers in Immunology 20189 2047. (https://doi.org/10.3389/fimmu.2018.02047)
15 Mano T, Sakamoto H, Fujita K, Makino M, Kakizawa H, Nagata M, Kotake M, Hamada M, Uchimura K, Hayakawa N, et al. Effects of thyroid hormone on catecholamine and its metabolite concentrations in rat cardiac muscle and cerebral cortex. Thyroid 19988 353-358. (https://doi.org/10.1089/thy.1998.8.353)

16 de Lau LM \& Breteler MM. Epidemiology of Parkinson's disease. Lancet: Neurology 20065 525-535. (https://doi.org/10.1016/S14744422(06)70471-9)

Received in final form 11 November 2020

Accepted 25 November 2020

Accepted Manuscript published online 27 November 2020 (c) 2021 The authors Published by Bioscientifica Ltd
This work is licensed under a Creative Commons Attribution-NonCommercial-NoDerivatives 4.0 Internationab ficense.ifica.com at 04/25/2023 11:18:26PM 